JURNAL KEBMUKAN SOSIIL EKONOWI KELAUTAN DAN PERIKANAN

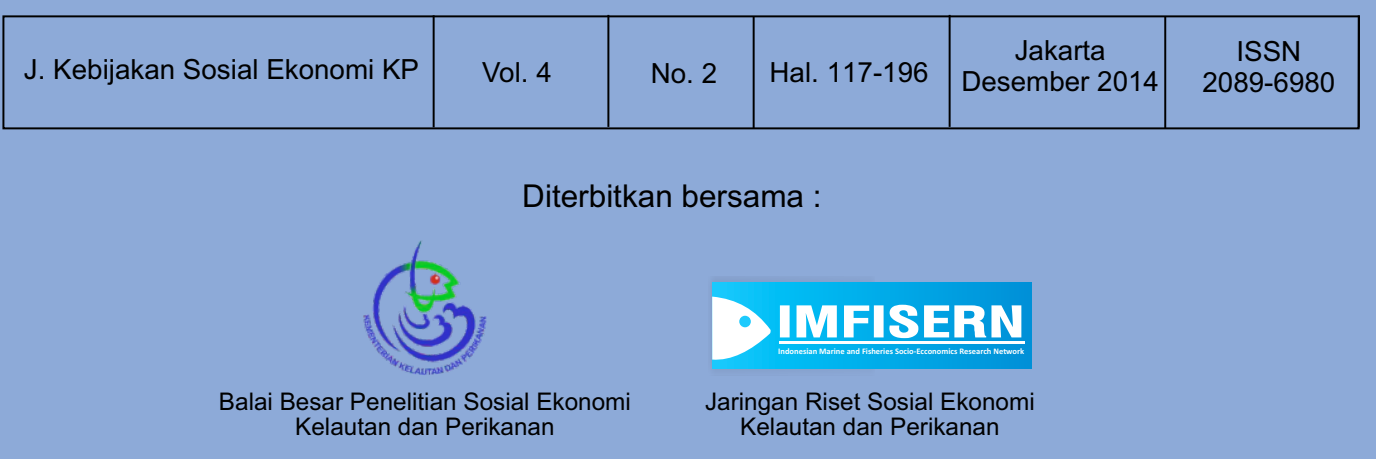

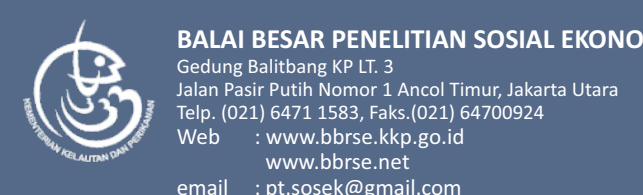




\section{KATA PENGANTAR}

Puji syukur kami panjatkan kepada Tuhan Yang Maha Esa, berkat RahmatNya telah diselesaikan Jurnal Kebijakan Sosial Ekonomi Kelautan dan Perikanan Volume 4 Nomor 2 Tahun 2014. Jurnal ini merupakan pengembangan dari Jurnal Kebijakan dan Riset Sosial Ekonomi Kelautan dan Perikanan yang telah terakreditasi berdasarkan keputusan Kepala LIPI No. 482/D/2011 tanggal 12 April 2011; secara spesifik memuat kebijakan sosial ekonomi kelautan dan perikanan.

Penerbitan jurnal ini didanai oleh Balai Besar Penelitian Sosial Ekonomi Kelautan dan Perikanan. Informasi yang ditampilkan meliputi: (i) Analisis Bioekonomi Sumber Daya Ikan Tenggiri (Scomberomorus commerson) di Perairan Kabupaten Indramayu Jawa Barat); (ii) Prakiraan Dampak Pengurangan Subsidi BBM Pada Usaha Perikanan (Studi Kasus di Pelabuhan Perikanan Samudera Nizam Zachman); (iii) Peluang Optimalisasi Pengembangan Budidaya Kepiting Soka di Wilayah KIMBis Cakradonya Kota Banda Aceh; (iv) Industrialisasi Perikanan Mendukung Ketahanan Pangan di Pedesaan Perairan Umum Daratan; (v) Dampak Letusan Gunung Kelud Terhadap Pelaku Usaha Perikanan di Kabupaten Kediri, Provinsi Jawa Timur; (vi) Kebijakan Pemerintah dan Adaptasi Masyarakat dalam Penanggulangan Dampak Banjir Terhadap Usaha Budidaya Ikan di Tambak; (vii) Ketepatgunaan Teknologi Budidaya Udang Secara Intensif di Tambak; (viii) Persepsi dan Strategi Adaptasi Nelayan Terhadap Isu Pencabutan Subsidi BBM.

Dengan diterbitkannya jurnal ini, diharapkan dapat memberikan informasi yang ada kepada masyarakat dan menambah wawasan ilmu pengetahuan di bidang perikanan dan kelautan. Saran dan masukan dari pembaca sangat diharapkan guna kesempurnaan penerbitan jurnal ini dimasa mendatang.

\section{Redaksi}




\section{JURNAL KEBIJAKAN SOSIAL EKONOMI KELAUTAN DAN PERIKANAN Volume 4 Nomor 2, Tahun 2014}

ANALISIS BIOEKONOMI SUMBER DAYA IKAN TENGGIRI (Scomberomorus commerson) DI PERAIRAN KABUPATEN INDRAMAYU JAWA BARAT)

Oleh : Lugas Lukmanul Hakim, Zuzy Anna dan Junianto

PRAKIRAAN DAMPAK PENGURANGAN SUBSIDI BBM PADA USAHA PERIKANAN

(Studi Kasus di Pelabuhan Perikanan Samudera Nizam Zachman)

Oleh : Subhechanis Saptanto dan Rizki Aprilian Wijaya

PELUANG OPTIMALISASI PENGEMBANGAN BUDIDAYA KEPITING SOKA DI WILAYAH KIMBis CAKRADONYA KOTA BANDA ACEH

Oleh : Freshty Yulia Arthatiani, Estu Sri Luhur, Armen Zulham dan Joni Haryadi

INDUSTRIALISASI PERIKANAN MENDUKUNG KETAHANAN PANGAN DI PEDESAAN PERAIRAN UMUM DARATAN

Oleh : Zahri Nasution dan Bayu Vita Indah Yanti

DAMPAK LETUSAN GUNUNG KELUD TERHADAP PELAKU USAHA PERIKANAN DI KABUPATEN KEDIRI, PROVINSI JAWA TIMUR

Oleh : Maulana Firdaus, Radityo Pramoda dan Maharani Yulisti.

KEBIJAKAN PEMERINTAH DAN ADAPTASI MASYARAKAT DALAM PENANGGULANGAN DAMPAK BANJIR TERHADAP USAHA BUDIDAYA IKAN DI TAMBAK

Oleh : Nendah Kurniasari dan Fatriyandi Nur Priyatna

KETEPATGUNAAN TEKNOLOGI BUDIDAYA UDANG SECARA INTENSIF DI TAMBAK Oleh : Bayu Vita Indah Yanti dan Zahri Nasution 
INDEKS ABSTRAK JURNAL KEBIJAKAN SOSIAL EKONOMI KELAUTAN DAN PERIKANAN ( ABSTRACT INDEX OF JOURNAL POLICY SOCIO-ECONOMICS MARINE AND FISHERIES )

ISSN 2089-6980

Vol. 4 No. 2, 2014

Kata kunci bersumber dari artikel. Lembar abstrak ini boleh diperbanyak tanpa izin dan biaya

UDC 316:639.2

ANALISIS BIOEKONOMI SUMBER DAYA IKAN TENGGIRI (Scomberomorus commerson) DI PERAIRAN KABUPATEN INDRAMAYU JAWA BARAT)

Lugas Lukmanul Hakim, Zuzy Anna dan Junianto

Penelitian ini memaparkan analisis bioekonomi pemanfaatan sumber daya ikan tenggiri pada berbagai rezim melalui Model Gordon Schaefer dengan model estimasi parameter biologi CYP serta arah kebijakan pengelolaannya di Kabupaten Indramayu. Penelitian ini dilaksanakan pada Bulan Februari-Juli 2014 dengan metode survey melalui analisis kuantitatif deskriptif. Hasil penelitian menunjukkan laju pertumbuhan intrinsik ( $r$ ) adalah 10,291 ton/tahun, koefisien daya tangkap (q) adalah 0,001673 ton/trip, daya dukung lingkungan adalah 250,028 ton/tahun, biaya (c) adalah 1,762 Rp/trip dan harga $(p)$ adalah 30,750 Rp/ton. Upaya maksimum lestari $\left(E_{M S Y}\right)$ yaitu 3076 trip/tahun dengan nilai produksi maksimum lestari $\left(\mathrm{h}_{\mathrm{MSY}}\right)$ sebesar 643,260 ton/tahun. Upaya MEY $\left(\mathrm{E}_{\mathrm{MEY}}\right)$ sebesar 2654 trip/tahun dengan produksi $\left(\mathrm{h}_{\mathrm{MEY}}\right.$ ) sebesar 631,141 ton/tahun. Upaya penangkapan perikanan terbuka (Eoa) adalah 5.308 trip/tahun dengan produksi $\left(\mathrm{h}_{\mathrm{OA}}\right)$ sebesar 304,689 ton/tahun. Kegiatan pemanfaatan menunjukkan tangkap lebih secara biologi dan ekonomi. Implementasi kebijakan dari penelitian ini adalah pembatasan upaya sebesar 314-736 trip, pengaturan armada alat tangkap jaring insang hanyut adalah 353-409 unit, payang 0-5 GT adalah 409-474 unit, payang > 5-10 GT adalah 73-85 unit, Jumlah tangkapan diperbolehkan ikan tenggiri sebesar 514,608 ton dengan kuota jaring insang hanyut sebesar 485,680 ton, payang 0-5 GT sebesar 5,772 ton, payang > 5-10 GT sebesar 23,156 ton, pengaturan teknis lainnya (perlindungan SDA dan DPI, pengawasan pemanfaatan sumber daya dan pungutan perikanan tangkap).

Kata Kunci: bioekonomi, Indramayu, kebijakan pengelolaan, tenggiri 
INDEKS ABSTRAK JURNAL KEBIJAKAN SOSIAL EKONOMI KELAUTAN DAN PERIKANAN

( ABSTRACT INDEX OF JOURNAL POLICY SOCIO-ECONOMICS MARINE AND FISHERIES )

ISSN 2089-6980

Vol. 4 No. 2, 2014

Kata kunci bersumber dari artikel. Lembar abstrak ini boleh diperbanyak tanpa izin dan biaya

UDC 639.2.06

PRAKIRAAN DAMPAK PENGURANGAN SUBSIDI BBM PADA USAHA PERIKANAN

(Studi Kasus di Pelabuhan Perikanan Samudera Nizam Zachman)

Subhechanis Saptanto dan Rizki Aprilian Wijaya

Pelabuhan Perikanan Samudera Nizam Zachman (PPSNZ) merupakan salah satu pelabuhan perikanan samudera di Indonesia yang terletak di Muara Baru, Jakarta Utara. Tujuan dari penulisan makalah ini adalah untuk menganalisis perkembangan kapal yang mendaratkan ikan di PPSNZ menurut jumlah kapal, stratifikasi GT, lokasi penangkapan (WPP) dan fluktuasi produksi ikan bulanan. Jenis data yang digunakan dalam penelitian adalah data sekunder yang berasal dari laporan tahunan, statistik perikanan dan berbagai referensi yang mendukung kegiatan penelitian. Analisis data yang dilakukan dengan menggunakan metode statistik deskriptif. Hasil penelitian menunjukkan bahwa jumlah produksi ikan yang didaratkan di PPSNZ pada tahun 2013 ada sebanyak $113.024 .086 \mathrm{~kg}$ dengan rata-rata produksi perbulan sebanyak $9.418 .674 \mathrm{~kg}$. Rata-rata kenaikan produksi ikan perbulan sebesar 6,10 \%. Kapal dengan ukuran 51-100 GT merupakan jenis kapal yang paling banyak mendaratkan ikan di PPSNZ. Bila dilihat dari lokasi penangkapannya, paling banyak yang menangkap ikan di WPP 711 yakni di perairan Laut Natuna. Pengurangan subsidi BBM diperkirakan memberikan dampak negatif kepada pelaku usaha perikanan khususnya yang berangkat dan mendaratkan ikan di PPS Nizam Zachman yakni berkurangnya kesejahteraan nelayan karena nelayan tidak melaut, peningkatan harga ikan karena berkurangnya supply ikan dari nelayan dan meningkatnya illegal fishing karena kapal-kapal di atas 30 GT sedikit yang melaut.

Kata Kunci: PPS Nizam Zachman, WPP, produksi ikan 
INDEKS ABSTRAK JURNAL KEBIJAKAN SOSIAL EKONOMI KELAUTAN DAN PERIKANAN ( ABSTRACT INDEX OF JOURNAL POLICY SOCIO-ECONOMICS MARINE AND FISHERIES )

\title{
ISSN 2089-6980
}

Vol. 4 No. 2, 2014

Kata kunci bersumber dari artikel. Lembar abstrak ini boleh diperbanyak tanpa izin dan biaya

\author{
UDC 639.518 \\ PELUANG OPTIMALISASI PENGEMBANGAN BUDIDAYA KEPITING SOKA \\ DI WILAYAH KIMBis CAKRADONYA KOTA BANDA ACEH
}

Freshty Yulia Arthatiani, Estu Sri Luhur, Armen Zulham dan Joni Haryadi

Kota Banda Aceh merupakan ibukota Provinsi Aceh yang berada di pulau Sumatera yang sangat potensial untuk pengembangan budidaya kepiting, namun masih menghadapi berbagai kendala dalam optimalisasi potensi yang dimiliki. Klinik IPTEK Mina Bisnis (KIMBis) Cakradonya di Kota Banda Aceh merupakan sebuah kelembagaan yang dibentuk pada tahun 2011 dengan tujuan peningkatan kesejahteraan masyarakat terutama di sektor kelautan dan perikanan. Tulisan ini bertujuan untuk dapat mendeskripsikan peranan KIMBis dalam mengoptimalisasi peluang pengembangan budidaya kepiting cangkang lunak yang biasa disebut kepiting soka. Penelitian dilaksanakan di Kota Banda Aceh yang merupakan wilayah Kerja KIMBis Cakradonya dengan analisis data dilakukan secara deskriptif kualitatif untuk menjelaskan kegiatan yang telah dilaksanakan oleh KIMBis dalam mengoptimalkan peluang pengembangan usaha kepiting soka. Hasil penelitian menunjukkan KIMBis Cakradonya berperan dalam mensosialisasikan peluang usaha kepiting soka terutama kepada stakeholders sehingga diharapkan dapat memberikan dukungan kebijakan bagi pengembangan usaha ini, selain itu KIMBis juga berperan dalam memperkenalkan penggunaan teknologi budidaya kepiting soka dan pengolahan limbah hasil budidaya kepiting yang diharapkan dapat meningkatkan produktifitas usaha. Namun optimalisasi peluang pengembangan kepiting soka mengalami berbagai kendala dari sisi teknologi, sumberdaya manusia modal dan juga input produksi. Oleh karena itu kedepannya diharapkan dapat dilaksanakan upaya tindak lanjut untuk mengatasi berbagai kendala yang dihadapi baik itu dari sisi pengadaan benih kepiting, maupun aplikasi penerapan teknologi yang efisien serta peningkatan kemampuan pembudidaya kepiting soka dalam mengakses permodalan sehingga usaha ini dapat berkembang secara optimal bagi peningkatan kesejahteraan masyarakat.

Kata Kunci: kepiting, soka, Banda Aceh, KIMBis 
INDEKS ABSTRAK JURNAL KEBIJAKAN SOSIAL EKONOMI KELAUTAN DAN PERIKANAN

( ABSTRACT INDEX OF JOURNAL POLICY SOCIO-ECONOMICS MARINE AND FISHERIES )

ISSN 2089-6980

Vol. 4 No. 2, 2014

Kata kunci bersumber dari artikel. Lembar abstrak ini boleh diperbanyak tanpa izin dan biaya

UDC 639.311

INDUSTRIALISASI PERIKANAN MENDUKUNG KETAHANAN PANGAN DI

PEDESAAN PERAIRAN UMUM DARATAN

Zahri Nasution dan Bayu Vita Indah Yanti

Potensi perikanan di wilayah perairan umum daratan di Indonesia yang mencapai 13,85 juta ha yang terdiri atas sungai dan rawa banjiran, danau alami, dan waduk. Saat ini perikanan tangkap perairan umum daratan (PUD) berfungsi sebagai sumber mata pencaharian bagi sebagian besar masyarakat di pedesaan, terutama nelayan, pembudidaya ikan di perairan umum, pengolah hasil perikanan dan pedagang ikan. Industrialisasi perikanan merupakan program pembangunan sektor perikanan pada saat ini merupakan lanjutan pelaksanaan program minapolitan. Penelitian bertujuan mengkaji penerapan industrialisasi perikanan dan dukungannya terhadap program ketahanan pangan di wilayah PUD telah dilakukan pada ekosistem sungai dan rawa, danau, dan waduk. Kajian dilakukan secara kualitatif dengan menganalisis lebih mendalam terhadap beberapa hasil penelitian yang terkait dengan program industrialisasi perikanan pada kawasan minapolitan perairan umum daratan. Hasil kajian menujukkan bahwa industrialisasi perikanan PUD apabila dijalankan dengan memperhatikan konsep pengelolaan PUD secara berkelanjutan melalui pendekatan pengembangan perikanan tangkap berbasis budidaya (CBF) dan pengendalian kegiatan budidaya, maka akan mendukung program ketahanan pangan nasional. Unsur keberlanjutan pada pelaksanaan program menjadi penting, karena jika sumber daya perikanan PUD dapat dimanfaatkan secara berkelanjutan, maka masyarakat tidak akan kesulitan dalam memenuhi kebutuhan pangan, dilihat dari aspek ketersediaan, akses, dan stabilitas ketersediaannya serta peningkatan daya belinya. Implikasi kebijakan yang diperlukan apabila industrialisasi perikanan PUD dilaksanakan dengan memperhatikan keberlangsungan sumber daya perikanan PUD, maka Dinas Kelautan dan Perikanan Kabupaten/Kota kiranya perlu ditingkatkan kapasitasnya dalam kaitannya dengan sistem dan kelembagaan pengelolaan sumberdaya perikanan PUD secara berkelanjutan.

Kata Kunci: industrialisasi, perikanan, ketahanan pangan, perairan umum daratan 
INDEKS ABSTRAK JURNAL KEBIJAKAN SOSIAL EKONOMI KELAUTAN DAN PERIKANAN ( ABSTRACT INDEX OF JOURNAL POLICY SOCIO-ECONOMICS MARINE AND FISHERIES )

ISSN 2089-6980

Vol. 4 No. 2, 2014

Kata kunci bersumber dari artikel. Lembar abstrak ini boleh diperbanyak tanpa izin dan biaya

UDC 639.2.05

DAMPAK LETUSAN GUNUNG KELUD TERHADAP PELAKU USAHA PERIKANAN DI KABUPATEN KEDIRI, PROVINSI JAWA TIMUR

Maulana Firdaus, Radityo Pramoda dan Maharani Yulisti

Penelitian ini bertujuan untuk mengkaji dampak letusan Gunung Kelud terhadap pelaku usaha perikanan khususnya di Kabupaten Kediri. Penelitian dilaksanakan pada bulan April-Mei 2014 dengan fokus lokasi penelitian di Kecamatan Pare, Kabupaten Kediri yang merupakan sentra penghasil benih ikan lele. Data primer dan sekunder digunakan dalam penelitian ini. Informan ditentukan dengan menggunakan teknik purposive sampling. Data yang diperoleh kemudian dianalisis secara kualitatif. Hasil penelitian menunjukkan bahwa letusan Gunung Kelud sangat berdampak pada masyarakat perikanan di Kabupaten Kediri baik secara sosial maupun ekonomi. Dampak secara sosial berupa perubahan status pembudidaya, perubahan struktur sosial dan perubahan mata pencaharian. Secara ekonomi, dampak letusan Gunung Kelud menyebabkan 274 pembudidaya di 16 kecamatan mengalami kerugian dengan total kerugian sebesar 3,9 milyar rupiah. Rata-rata nilai kerugian yang dialami oleh setiap pembudidaya adalah 14,4 juta rupiah per orang yang meliputi kematian ikan, kematian benih ikan, kematian induk ikan, rusaknya kolam ikan, serta rusaknya peralatan budidaya.

Kata Kunci: letusan, Gunung Kelud, perikanan, Kabupaten Kediri 
INDEKS ABSTRAK JURNAL KEBIJAKAN SOSIAL EKONOMI KELAUTAN DAN PERIKANAN

( ABSTRACT INDEX OF JOURNAL POLICY SOCIO-ECONOMICS MARINE AND FISHERIES )

ISSN 2089-6980

Vol. 4 No. 2, 2014

Kata kunci bersumber dari artikel. Lembar abstrak ini boleh diperbanyak tanpa izin dan biaya

UDC 639.32

KEBIJAKAN PEMERINTAH DAN ADAPTASI MASYARAKAT DALAM PENANGGULANGAN DAMPAK BANJIR TERHADAP USAHA BUDIDAYA IKAN DI TAMBAK

Nendah Kurniasari dan Fatriyandi Nur Priyatna

Penelitian bertujuan memberikan gambaran mengenai strategi mitigasi yang dilakukan oleh pemerintah serta strategi adaptasi masyarakat dalam menghadapi dan menanggulangi dampak banjir. Penelitian dilakukan di wilayah pantai utara Jawa Barat Kabupaten Subang dan Kabupaten Karawang. Jenis data yang diambil adalah data primer dan data sekunder. Data primer diambil melalui teknik wawancara mendalam dan observasi dengan pelaku usaha budidaya ikan di tambak, sementara data sekunder diambil melalui wawancara dan kaji literatur terhadap dokumen Badan Penanggulangan Bencana Nasional dan data perikanan Dinas Kelautan dan Perikanan. Data dianalisis secara kualitatif dengan mengaitkan satu fenomena dengan fenomena lainnya berdasarkan analisis logik. Hasil analisis kemudian dijadikan bahan untuk merumuskan rekomendasi penanggulangan dampak banjir. Upaya pemerintah dalam melakukan mitigasi bencana banjir adalah dengan mengeluarkan UU No.24/ 2007, PP No. 21/2008, PP No.22/2008, PP No. 23/2008, dan Permen KP No.12/2014. Beberapa hal yang perlu diatur lebih lanjut adalah sumber pendanaan harus dialokasi secara khusus di dalam pos anggaran kementerian agar tidak mengganggu pos anggaran lainnya serta tata kelola tentang penanggulangan bencana alam di sektor kelautan dan perikanan seharusnya bersifat menyeluruh dan berjenjang dari mulai tingkat pusat hingga ke daerah yang melibatkan secara bersama seluruh elemen pemerintah dan masyarakat, terutama di tingkat daerah.Pada tataran masyarakat, jaringan sosial merupakan bentuk adaptasi pembudidaya ikan dalam menanggulangi dampak banjir. Jaringan sosial tersebut bisa menjamin sumber modal, sumber tenaga kerja, dan sumber iptek. Intervensi lebih lanjut dibutuhkan dalam penanggulangan tanggap darurat dan rehabilitasi sarana produksi, karena relasi yang sekarang terbentuk belum menyentuh kedua aspek ini.

Kata Kunci: mitigasi, adaptasi, banjir, budidaya ikan 
INDEKS ABSTRAK JURNAL KEBIJAKAN SOSIAL EKONOMI KELAUTAN DAN PERIKANAN ( ABSTRACT INDEX OF JOURNAL POLICY SOCIO-ECONOMICS MARINE AND FISHERIES )

ISSN 2089-6980

Vol. 4 No. 2, 2014

Kata kunci bersumber dari artikel. Lembar abstrak ini boleh diperbanyak tanpa izin dan biaya

UDC 639.4

KETEPATGUNAAN TEKNOLOGI BUDIDAYA UDANG SECARA INTENSIF DI TAMBAK

Bayu Vita Indah Yanti dan Zahri Nasution

Ketepatgunaan teknologi merupakan salah satu indikator bahwa teknologi yang diintroduksi dapat dimanfaatkan oleh masyarakat sesuai dengan kondisi yang ada pada masyarakat. Untuk megetahui ketepatgunaan teknologi yang diterima oleh pengguna, dapat digunakan 7 (tujuh) indikator ketepatgunaan teknologi yang dikembangkan dari sifat dan ciri teknologi diintroduksi. Penelitian ini menggunakan pendekatan analisis kebijakan. Teknologi yang dievaluasi adalah teknologi yang diperkenalkan oleh Kementerian Kelautan dan Perikanan (KKP) melalui Direktorat Jenderal Perikanan Budidaya (DJPB) pada demfarm budidaya udang di tambak secara intensif. Studi ini dilakukan sejak April hingga Juni 2014, termasuk verifikasi lapang ke lokasi percontohan di wilayah Kabupaten Karawang, Jawa Barat. Analisis dan interpretasi data dilakukan secara deskriptif. Hasil penelitian menunjukkan bahwa teknologi budidaya udang secara intensif dapat dikatakan hanya tepat dikembangkan pada petambak yang memiliki modal besar dan memiliki pengetahuan dan pengalaman dalam melaksanakan budidaya udang. Pengembangan budidaya udang secara intensif harus dilakukan melalui kerjasama antara petambak udang dan investor dan pemerintah melalui suatu pola yang disepakati secara bersama.

Kata Kunci: ketepatgunaan teknologi, budidaya udang, intensif, demfarm 
INDEKS ABSTRAK JURNAL KEBIJAKAN SOSIAL EKONOMI KELAUTAN DAN PERIKANAN

( ABSTRACT INDEX OF JOURNAL POLICY SOCIO-ECONOMICS MARINE AND FISHERIES )

ISSN 2089-6980

Vol. 4 No. 2, 2014

Kata kunci bersumber dari artikel. Lembar abstrak ini boleh diperbanyak tanpa izin dan biaya

UDC 639.2 .05

PERSEPSI DAN STRATEGI ADAPTASI NELAYAN TERHADAP ISU PENCABUTAN SUBSIDI BBM

Rizki Aprilian Wijaya dan Subhechanis Saptanto

Bahan Bakar Minyak (BBM) merupakan input produksi penting bagi nelayan. Pada tahun 2014, terdapat wacana untuk menghapus subsidi BBM untuk nelayan. Tulisan ini bertujuan untuk menganalis persepsi nelayan terhadap kemungkinan kebijakan pencabutan subsidi BBM dan menganalisis strategi adaptasi nelayan terhadap kemungkinan pencabutan subsidi BBM. Lokasi penelitian berada di Pelabuhan Perikanan Samudera (PPS) Nizam Zachman dan Pelabuhan Pendaratan Perikanan (PPI) Muara Angke di Provinsi D.K.I. Jakarta. Penelitian dilakukan melalui pendekatan kualitatif. Pengumpulan data dilakukan melalui wawancara mendalam (in-depth Interview) kepada petugas pelabuhan, tokoh nelayan, pemilik dan nahkoda kapal perikanan. Analisis data dilakukan secara deskriptif. Hasil kajian menunjukan bahwa sebagian besar nelayan (khususnya nelayan kecil) menolak terhadap kebijakan pencabutan subsidi BBM. Jenis strategi adaptasi nelayan terhadap kemungkinan diberlakukannya kebijakan pencabutan subsidi BBM diantaranya adalah tidak melakukan aktivitas melaut dalam jangka waktu tertentu, beralih pekerjaan ke sektor non perikanan maupun sektor perikanan lainnya dan mencari solusi pemecahan masalah melalui kelompok.

Kata Kunci: persepsi nelayan, strategi adaptasi, pencabutan subsidi BBM 